NURSING AND HEALTH CARE MANAGEMENT AND POLICY

\title{
Supporting frail older people and their family carers at home using information and communication technology: cost analysis
}

\author{
Lennart Magnusson MSc RN \\ Project Manager, Lecturer, Health Sciences, University College of Borås, Borås, Sweden \\ Elizabeth Hanson BA PhD RN \\ Senior Lecturer, Aldre Vast Sjuharad Research Centre, University College of Borås, Borås, Sweden
}

Accepted for publication 13 January 2005

Correspondence:

Lennart Magnusson,

University College of Borås,

Allegatan 1,

Borås,

S-50190,

Sweden.

E-mail: lennart.magnusson@hb.se
MAGNUSSON L. \& HANSON E. (2005) Journal of Advanced Nursing 51(6), 645-657

Supporting frail older people and their family carers at home using information and communication technology: cost analysis

Aim. This paper describes a cost analysis of a home-based support service for frail older people and their family carers in two municipalities in West Sweden and using information and communication technology.

Background. A key challenge facing nurse managers across Europe is an increasingly aged population, combined with reduced numbers of young adults of working age. New solutions are needed to provide quality, cost-effective community care services to frail older people and their family carers.

Methods. A case study methodology involving five families was used, and included a detailed cost description of the technology-based service compared with usual services. Cost data were collected in June 2002. This work formed part of a larger project exploring the impact of a technology-based service known as, Assisting Carers using Telematics Interventions to meet Older Persons' Needs (ACTION). In addition to cost data, information was gathered on the quality of life of frail older people and their family carers, and the job satisfaction and work methods of nurses and other practitioners based in the community. The cost analysis comprised a description of the family and their caring situation, the perceived benefits of the telematic based support service and an assessment of its impact on the use of other care services. These analyses were carried out with the help of needs assessors who were known to the families, and nurses working in the ACTION call centre. All results were validated by the five participating families.

Results. Cost savings were achieved in all cases, and the benefits to older people and their carers were also considerable. As a result of the cost analysis and overall evaluation data, ACTION has been implemented as a mainstream service in the municipalities involved.

Conclusion. Researchers, nurses, other practitioners and community care managers can work together with frail older people and their family carers to develop quality, cost-effective support services that reduce demands on staff whilst providing benefits to users.

Keywords: community nursing, costs, family carers, frail older people, information and communication technology, quality of life 


\section{Introduction}

\section{Support for older people and their family carers in Sweden}

With an increasingly ageing population and reduced numbers of young adults available to work in health and social care, community care managers face serious challenges in recruiting and retaining competent nurses and other professional carers to run existing care services for older people (Donelly 2002). In Sweden over the last 10 years, as in other northern and western countries in Europe, community care policy has advocated the principle of 'ageing in place', arguing that the majority of older people wish to remain in their own homes. Thus, the numbers of nursing home beds have been greatly reduced and the majority of frail older people in Sweden who require help and support with activities of daily living tend to remain in their own homes with the help of their family and friends, as well as home care services (Johansson et al. 2003).

Over the last decade, government policy in Sweden has increasingly mirrored countries such as the United Kingdom (UK) and North America, so that community care in reality means family care, with the 'lion's share' of caring now carried out by relatives (Board of Health and Welfare Sweden 2004a). Thus, support for family carers is a policy priority in Sweden (Board of Health and Welfare Sweden 2002). However, as with other countries providing family carer support services, it is recognized that there is room for improvement in the quality and range of services available (Board of Health and Welfare Sweden 2004b).

Also, despite the voluminous literature in the field of family caregiving, there is a dearth of evidence about the effectiveness of current approaches (Nolan et al. 2003). Thus, there is an urgent need to find new and more effective ways of supporting older people, their family carers, and practitioners more effectively (Schulz 2001). The potential role of technology in enhancing the independence of older people living at home is increasingly being recognized in both the UK (Audit Commission 2004) and in Sweden (Board of Health and Welfare Sweden 2004b). Many such initiatives are currently being tested in the United States of America, where a range of nurse-led telehealth and telecare services has been designed to maintain older people at home for as long as possible, whilst also supporting their family carers (Magnusson et al. 2004). However, such initiatives have often been professionally-driven and developed largely without involvement of user groups, which increases the risk, already apparent with traditional services, of support not being attuned to the needs and preferences of older people and their family carers, resulting in services being under-used or rejected by service users (Magnusson et al. 2004).

This paper considers an information and technology-based (ICT) project (Assisting Carers using Telematics Interventions to meet Older Persons' Needs, ACTION) that was userdriven from the outset. It places particular focus on the cost benefits of such a service and considers its transition from a pilot project to a mainstream service.

\section{Background}

\section{The ACTION concept}

The ACTION concept is an ICT-based support service for older people and their family carers and arose from the EU project ACTION, which developed and tested the service in Sweden, England, Northern Ireland, the Republic of Ireland and Portugal (1997-2000). Following the initial project, funding was secured from the Ministry of Health and Social Affairs to further develop and test the ACTION services in Sweden (2000-2002). A participatory research design was adopted in the EU ACTION study (Hanson et al. 1999a, 2000, Tetley \& Hanson 2000) and further refined in the Swedish ACTION project (Magnusson et al. 2002a). A summary of the ACTION research methods is presented in Figure 1.

ACTION was designed to enable family carers to access education, information and support in relation to their current caring situation and over the course of their caring trajectory (Nolan et al. 1996, Hanson et al. 1999b). It was intended to empower families to be informed about the choices available to them and to engage in informed decisionmaking about their caring situation so as to avoid the

- User working groups
- Individual interviews
- Focus group interviews
- User trials
- Questionnaires
- Log diaries
- Field Notes
- Field testing in people's homes and community care settings
(Based on Magnusson et al. 2002a, Hanson et al. 1999a, 2000)

Figure 1 Summary of the research methods used in the Assisting Carers using Telematics Interventions to meet Older persons' Needs (ACTION) projects. 
disempowering effects of crisis-oriented care, which tended to predominate practice (Hanson \& Clarke 2000, Qureshi et al. 2000).

ACTION consists of a range of multimedia caring programmes that families access via their TV sets (in the EU project) and subsequently via their personal computers (PCs) (in the Swedish project). The programmes were based on carers' needs identified from the empirical caregiving literature and from extensive user consultation in the project, namely, caring skills in daily life, planning ahead, respite care services, financial and economic support and coping strategies (Magnusson et al. 1998). Videophone facilities were also provided, which enabled families to have visual and oral contact with professional carers and other families involved in the project. This was achieved via a small camera on top of the PC, the installation of videoconferencing hardware on the computer and ISDN2b lines in families' homes. Finally, families also had access to Internet and e-mail facilities.

At the request of the families, Swedish ACTION services were extended to include more multimedia educational caring programmes. Videophone access to professionals was improved by establishing two call centres run by nurses, who provided dedicated advice and support to families. The Swedish ACTION services operated via a computer connected to ISDN $2 \mathrm{~b}$ lines and the Internet (Magnusson et al. 2002b).

A typical user initially accessed the multimedia programmes to increase their knowledge and caring skills, and referred to them again as their caring situation changed. They had frequent contact via the videophone with other families to exchange news and to support each another. They also had regular contact with the call centre nurses to share how they were feeling and to ask for advice on an 'as needed' basis. During spare moments, they surfed the Internet and emailed their children/grandchildren, who lived some distance away (Magnusson et al. 2002a).

Overall the Swedish study demonstrated the positive impact of ACTION for those family carers who wished to care for their older relatives at home. A summary of the key findings is presented in Figure 2.

The study, together with a review of the literature in the field, identified a range of factors that appear critical to the success of such initiatives, as well as caveats to their use.

Frail older people and their family carers

- Family carers increased their competence, satisfaction and sense of security in their caregiving role as a result of using ACTION (Magnusson et al. 2005).

- Frail older people and their family carers became less isolated as a result of developing informal support networks with other ACTION families (Magnusson et al. 2002a).

- ACTION has the potential to empower older people and their carers and to enrich the caring relationship (Hanson et al. 2002).

- ACTION helps to increase the social inclusion of frail older people and their carers who are traditionally excluded from the benefits of information and communication technology (ICT) (Magnusson et al. 1999).

- Optimal benefit from ACTION occurs when the support service is introduced as early as possible within the caring process (Hanson \& Clarke 2000).

- It is more likely that ACTION is accepted by older people if it is introduced as a tool to help families access education, information and support in their own home, rather than emphasizing technology per se (Magnusson \& Hanson 2003).

- Frail older people and their family carers are happy to use ICT provided that it is easy to use, easy to learn, easy to understand and of direct benefit to them (Magnusson et al. 1999).

Nurses

- ACTION call centre nurses reported increased job satisfaction and client satisfaction as a result of working in partnership with families (Magnusson et al. 2005).

- Some professionals working in traditional care settings for older people fear that new technology will replace them and value direct human contact (Magnusson et al. 2005).

Research methods and theory building

- Direct involvement of frail older people and their family carers during the research and development process leads to high levels of user acceptance (Hanson et al. 2000, Andersson et al. 2002, Magnusson \& Hanson 2004).

- In-depth user consultation with family carers can lead to the development of meaningful theory which then acts as a useful framework for multi-media education programmes for carers (Hanson et al. 1999b).

Figure 2 Summary of the key findings from the Assisting Carers using Telematics Interventions to meet Older persons' Needs (ACTION) projects. 


\section{Critical success factors identified from the empirical literature}

Probably the most important factor of all is that older people and their carers are actively involved in the design of the ICT, enhancing the possibility of the content being seen as relevant to their needs.

Older people's attitudes towards new technology are also a crucial factor. Work carried out in ACTION strongly indicates that, contrary to public stereotypes, older people are not inherently negative about technology. Indeed, if they and their carers can see the benefits of technology, and are assisted and supported to learn basic skills, then they are likely to adopt it enthusiastically (Magnusson et al. 1999).

Conversely, for those who are sceptical about potential benefits, and/or for those carers who are possibly reluctant to care for an older relative at home, then ACTION and similar initiatives may not be appropriate (Magnusson et al. 2005). This points to the need for careful assessment and regular monitoring of the best way to meet the needs of older people and their family carers (Board of Health and Welfare Sweden 2004b).

A key drawback to the mainstream implementation of ICT in health and social care for older people is the lack of a technical infrastructure and a business model (Cowan \& Turner Smith 1999, Curry et al. 2003, Audit Commission 2004). There is also an additional barrier to the transferability of existing services, as the majority of ICT-based projects are locally-based pilot studies (Darkins \& Cary 2000). As a result there is often lack of co-ordination between projects, which leads to duplication of effort and incompatibility of equipment. There are also cost considerations in relation to the cultural adoption of ICT-based interventions, given that the majority of current initiatives are predominantly US-based (Magnusson et al. 2004).

Recent reviews of the 'state of the art' in relation to ICT point to the relatively weak evidence base to support telemedicine interventions, particularly with regard to cost (Håkansson \& Gavelin 2000, Mair et al. 2000, Wootton 2001, Hailey et al. 2002, Whitten et al. 2002, Jennett et al. 2003). Mair et al. (2000) and Whitten et al. (2002) identified key weaknesses in the published literature and posed 10 fundamental questions that should be taken into consideration when designing cost effectiveness studies in telemedicine. These are presented in Figure 3.

Against this background, in this paper we present the results of a cost analysis carried out within the Swedish ACTION project. The study findings will be discussed using the above criteria as a framework.
- Is there a clear hypothesis?

- Is there a clear statement regarding the perspective from which cost effectiveness is assessed?

- Is the methodology of high quality and appropriate?

- Is the comparator appropriate?

- Is the quality of the medical evidence adequate?

- Are appropriate costs and benefits considered?

- Has an adjustment of costs and benefits been made for differential timing?

- Is a marginal analysis undertaken?

- Is a sensitivity analysis performed?

- Is the analysis appropriate to the local environment?

Figure 3 Key questions to consider when designing cost-effectiveness studies in telemedicine (based on Mair et al. 2000, Whitten et al. 2002).

\section{The study}

\section{Aim}

The primary aims of ACTION are to increase the autonomy, independence and quality of life of frail older people and their family carers by providing information, education and support via the use of ICT in their own homes. The question addressed here is whether the use of ACTION by participating families will reduce their potential use/costs of other services whilst maintaining or enhancing their quality of life.

\section{Methodology}

The cost analysis work was conducted in Autumn 2002, was a sub-study within the overall Swedish ACTION project, and was in essence a cost description. Øvretveit (1998) defines a cost description as 'a measurement of the costs of one thing, or of more than one, in a way which allows an explicit or implicit comparison of costs' (Øvretveit 1998, p. 168). A cost description is often the first step in a full economic evaluation and is appropriate when developing and testing a new service, such as ACTION. A full economic evaluation, including costeffectiveness, cost-utility and cost-benefit analyses is considered more appropriate when a service has been refined and is ready for testing in the form of a full randomized controlled trial (Flatley Brennan et al. 1995). A case study design was employed for the cost description analysis, which means that each selected family represented a case and the descriptive data concerning care service costs and the ACTION intervention costs was analysed with regard to the family's perceived benefits of ACTION, resulting in a hypothetical cost assessment of usual service costs. In this way, the 
methods of the instrumental case study was employed, as the main area of interest was to gain a comprehensive description of the costs of ACTION compared with usual care services for older people and their family carers. Cases were chosen that helped to advance understanding of the potential of ACTION in relation to cost savings. However, although we simultaneously studied five cases, each case study was an indepth inquiry into a single case. As Stake (2000) acknowledged, 'The case is still looked at in depth, its contexts scrutinized, its ordinary activities detailed, but all because this helps the researcher to pursue the external interest' (p. 237).

\section{Participants}

The sample for the cost description study was purposive and the ACTION call centre nurses were asked to select five participating families for whom they considered ACTION had a major impact in preventing increased care costs. The five families were selected from a total of 34 who participated in the ACTION project. The costs for these five families were used to calculate the final average hypothetical cost saving calculations for the total sample. Families were recruited from two municipalities in West Sweden. One municipality was an urban area with 100,000 inhabitants, with one district of 10,500 inhabitants participating in the project. The second was a mixed urban and rural area with 33,000 inhabitants. In both areas, $13 \%$ of the inhabitants were 65-79 years of age and 6\% were 80 years of age and older.

\section{Data collection}

Following approval from the five families, the needs assessors (who knew the families involved), together with the ACTION call centre nurses, undertook a preliminary cost analysis for each of the five case families focusing on the following three areas:

- A description of the family and their caring situation.

- A description of the families' perceived benefits from ACTION.

- An assessment of the impact on ACTION on care service costs.

A description of the family and their caring situation was collated with the families' consent from existing general background demographic project data. The description of the families' perceived benefits from ACTION was gained from project interview data with the families. The needs assessors were then asked to make careful assessments of how many care services the five case families would have needed if they had not had the ACTION service. The descriptions, together with the care assessment, were collected by the first author and validated by each family. The validation was carried out at a joint meeting in the family's own home between the family, the needs assessor, the first author and an ACTION call centre nurse.

Based on the results of these hypothetical cost assessments, an estimate of the average cost saving per family based on the total sample of 34 ACTION families was made. This calculation was based on the main study data, which demonstrated a moderate impact from ACTION for the majority of families and little or no impact for a minority (Magnusson et al. 2005).

The costs for different kinds of usual care services were obtained from the financial departments in the two participating municipalities (N.B. the amount that the families would have had to contribute to the different kinds of caring services were not included in the case studies or in the final results). The ACTION service costs were therefore based on real actual costs for equipment, communication, technical support and the ACTION call centre. The use and cost for telecommunication and Internet were based on information from the telecom company's invoices for the period July 20001 to June 2002. The costs for development and maintenance of the ACTION programmes were based on estimations from previous experience within the ACTION project.

\section{Validity and reliability}

The case study cost analyses were validated by the five participating families. This was carried out by presenting a preliminary cost analysis to each family prior to the joint meeting. At the joint meeting, the draft analysis was presented and family members were asked if they were in agreement with the assessment and if they were satisfied with the way in which their caring situation and benefits from ACTION had been documented. All families agreed with the descriptions of their caring situation and the benefits of ACTION, with only minor adjustments. Four families agreed to their cost assessment. However, one family did not agree with the amount of services the needs assessor had suggested, and the calculation was adjusted to accommodate this difference.

The case cost analyses can be said to be reliable as they included the most recent figures for care services available from the municipality and the analyses were carried out by the first author in collaboration with independent, experienced needs assessors who knew the families situation, thereby minimizing potential errors. 


\section{Ethical considerations}

Ethical approval for the Swedish ACTION study was obtained from the ethical review committee at the Faculty of Medicine, University of Gothenburg. For the cost analysis, the ACTION call centre nurses carefully explained this substudy to the five selected families, reassuring them that their names would not appear on any reports or articles arising from the study and that wherever possible their identity would be protected. It was also explained that they would receive a draft of their cost analysis which they could accept, modify or reject as appropriate. Also, they would have an opportunity to discuss openly their views about the cost analysis during a home visit with the needs assessor and call centre nurse. It was emphasized that they could decline to take part or could withdraw at any time without any repercussions on the care they received or with regard to the overall ACTION study.

\section{Results}

The results consist initially of an itemization of the operational costs for statutory care services for older people and their family carers, followed by an itemization of operational costs for the ACTION service. A summary of the five cost case studies is presented (N.B. pseudonyms have been used to protect the identity of the families). Finally, a hypothetical calculation to explore the average cost savings per family (out of the total sample of 34 families) of using ACTION is presented.

The costings are presented in Swedish Crowns (SEK) and the exchange rate on 28 June 2002 was 9.08 SEK for one Euro (EURO), 14.01 SEK for one British pound (GBP) and 9.16 SEK for one US dollar (USD) (The Swedish Riksbank).

\section{Usual care service costs}

The costs for usual care services for older people and their family carers are based on figures for 2001 obtained from the financial departments in the participating municipalities. These constituted the most current figures available at the time the cost analysis was carried out. See Table 1.

\section{Costs for the ACTION service}

The costs of offering a family ACTION were 25,800 Swedish Crowns (SEK) per year (2150 SEK per month) (see Table 2).

The costs for a computer, videophone hardware, camera and appropriate software and antivirus programmes were approximately 25,000 SEK based on 'off the shelf' prices in
Table 1 Usual Care Service Costs year 2001 for the participating municipalities

\begin{tabular}{lcc}
\hline & Municipalities & \\
\cline { 2 - 3 } & Municipality 1 & Municipality 2 \\
\hline Attendance allowance & $1176 \mathrm{SEK} /$ month & $1210 \mathrm{SEK} / \mathrm{month}$ \\
Home help & $280 \mathrm{SEK} / \mathrm{hour}$ & $301 \mathrm{SEK} / \mathrm{hour}$ \\
$\begin{array}{l}\text { Day care - dementia } \\
\begin{array}{l}\text { Day care - physically frail } \\
\text { and rehabilitation }\end{array}\end{array}$ & $660 \mathrm{SEK} /$ day \\
Respite care & $650 \mathrm{SEK} /$ day & $320 \mathrm{SEK} /$ day \\
Nursing home & $1250 \mathrm{SEK} /$ day & $1250 \mathrm{SEK} /$ day \\
\end{tabular}

SEK, Swedish Crowns.

Exchange rate 28.6.2002: 1 EUR = 9.08 SEK, 1 GBP = 14.01 SEK, 1 USD $=9 \cdot 16$ SEK (The Swedish Riksbank).

This figures comprises all costs, including general administration for all services except attendance allowance.

Table 2 Cost for the ACTION service per family per year

\begin{tabular}{lr}
\hline & \multicolumn{1}{c}{ Cost } \\
\hline $\begin{array}{l}\text { Equipment incl. software (based on writing of } \\
\quad \text { within } 36 \text { months) }\end{array}$ & 8400 \\
Technical support & 1000 \\
Telecommunication and Internet* & 6000 \\
ACTION program (based on 500 users) & 2400 \\
Local call centre (based on 50 users) & 8000 \\
Total & 25,800 \\
\hline
\end{tabular}

In Swedish Crowns (SEK).

Exchange rate 28.6.2002: $1 \mathrm{EUR}=$ 9.08 SEK, $1 \mathrm{GBP}=14.01 \mathrm{SEK}, 1$ USD $=9 \cdot 16$ SEK (The Swedish Riksbank).

*An installation cost per user with 5000 SEK has to be added.

Sweden in March 2001. Installation of ISDN 2b was carried out by the Swedish Telecom Company Telia at an average cost of 5000 SEK, and the equipment was installed by the ACTION call centre nurses. Nevertheless, occasionally technical problems occurred which required the skills of a technician. This was estimated as a technical support consultation once or twice a year, with a yearly cost of 1000 SEK per family.

The actual average costs for Internet and video communication were 458 SEK per month, based on figures for July 2001-June 2002, which in the following calculations have been rounded to 500 SEK per month (6000 SEK per year). Table 3 presents the Internet and video communication costs for the 34 users.

The estimated cost for programme development and maintenance was 1,200,000 SEK per year, which gave rise to a cost of 2400 SEK per family per year based on 500 users. These figures were based on the premise (from our research and development work experience over the last 7 years) that 
Table 3 Costs for using telecommunication and Internet per family per month, during the period July 2001-June 2002

\begin{tabular}{|c|c|c|c|c|c|c|}
\hline & \multicolumn{2}{|l|}{ Internet } & \multicolumn{3}{|c|}{ Telecommunication } & \multirow[b]{2}{*}{ Total } \\
\hline & Time (hour:minute) & Cost (SKR) & Calls (number) & Time (hour:minute) & Cost (SKR) & \\
\hline Mean & $18: 33$ & 247 & 10 & 01:04 & 211 & 458 \\
\hline Lowest & $00: 17$ & 102 & 1 & 00:01 & 200 & 303 \\
\hline Highest & 101:10 & 854 & 44 & $06: 29$ & 281 & 1135 \\
\hline
\end{tabular}

In Swedish Crowns (SEK).

Exchange rate 28.6.2002: 1 EUR = 9.08 SEK, 1 GBP = 14.01 SEK, 1 USD = 9.16 SEK (The Swedish Riksbank).

Table 4 Total cost for the local call centre per year

\begin{tabular}{lr}
\hline & \multicolumn{1}{c}{ Cost } \\
\hline Salary, including social insurance and vacations & 340,000 \\
Housing costs & 15,000 \\
ACTION-equipment (based on writing of within & 8400 \\
36 months) & 7200 \\
Telecommunication and Internet & 29,400 \\
Additional: travel, education and social activities with & \\
$\quad$ the families & 400,000 \\
\hline
\end{tabular}

In Swedish Crowns (SEK).

Exchange rate 28.6.2002: 1 EUR $=9 \cdot 08$ SEK, $1 \mathrm{GBP}=14 \cdot 01$ SEK, 1 USD $=9 \cdot 16$ SEK (The Swedish Riksbank).

there was one nurse and one IT-worker working full-time on programme development and maintenance in order to guarantee 'state of the art' work. Costs for equipment, office and administration were also included in the yearly figures.

The total cost for a call centre was 400,000 SEK per year for providing a service for 50 families. This was based on estimations from the empirical literature and from experience in the ACTION call centre that one nurse working full-time could support approximately 50 families; this was a sum of 8000 SEK per year per family. The costs for the call centre are specified in Table 4.

\section{Summary results of the cost case studies}

A summary of the cost case study data is presented in Table 5; this gives an overview of each case study family in relation to their individual caring situation, followed by their perceived benefits from ACTION and, finally, a condensed cost assessment.

\section{Results of the hypothetical cost calculations}

The majority of the 34 family carers taking part in the overall project considered that their quality of life had increased through using the ACTION service (Magnusson et al. 2005). From the case study data, it was clear that the five families benefited considerably from ACTION. The estimated cost description data revealed that, for these five families, the average net cost savings for the municipalities were 217,700 SEK per family per year (see Table 6).

However, amongst the total project sample of 34 family carers there were five families who had very little or no use of ACTION (Magnusson et al. 2005) and as a result there were no cost savings at all. For these families, ACTION resulted in a cost of 25,800 SEK per year. Our estimation is that, for the remaining 24 families, the cost savings were in the region between the average highest and lowest cost savings.

Thus, we calculated the average cost savings for all 34 families involved in the project by taking the average cost saving between the five families where there was a high cost saving of 217,700 SEK per year and those where there was no cost saving - 25,800 SEK per year. The average cost saving was then calculated as 96,000 SEK per family per year.

\section{Discussion}

The methodology and results of our cost description study will now be discussed using the criteria for evaluating cost effectiveness studies in telemedicine suggested by Mair et al. (2000) and Whitten et al. (2002) in their systematic literature review of empirical research in the field (see Figure 3 ).

The first question to consider is whether the methodology was appropriate and of high quality. It needs to be acknowledged that the study had a number of limitations, the main one being the small number of cases involved. Therefore it can best be seen as a feasibility study. A further weakness in the cost study design was that the costs for the families themselves were not taken into account. Another limitation was the lack of a control group with which the actual costs could be compared. As an alternative, a comparison was made between the costs for the actual service for the families, including ACTION, and the cost for the estimated services the families would have needed if they had not had ACTION. Clearly, this is a difficult calculation and there is a risk that 


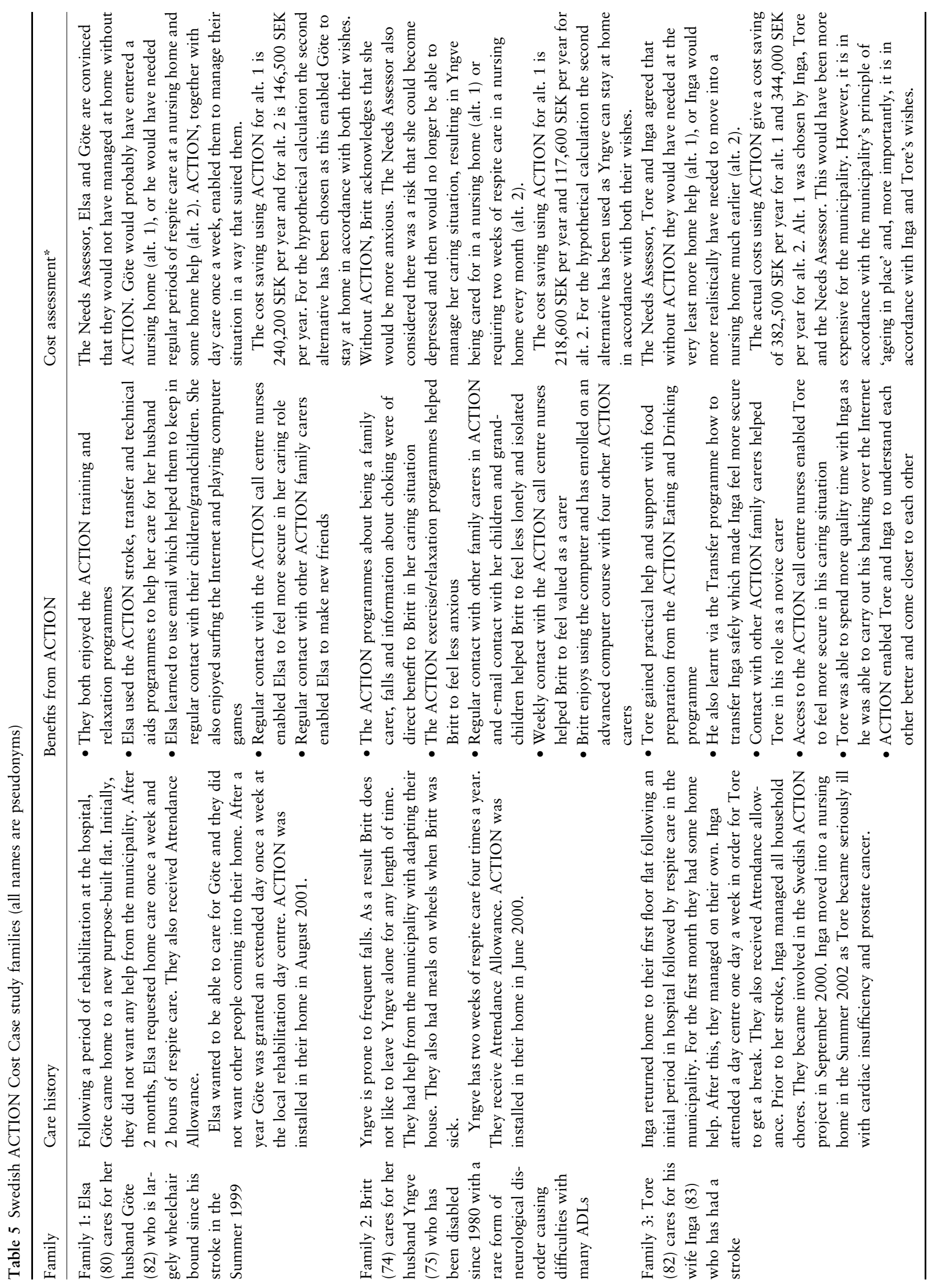




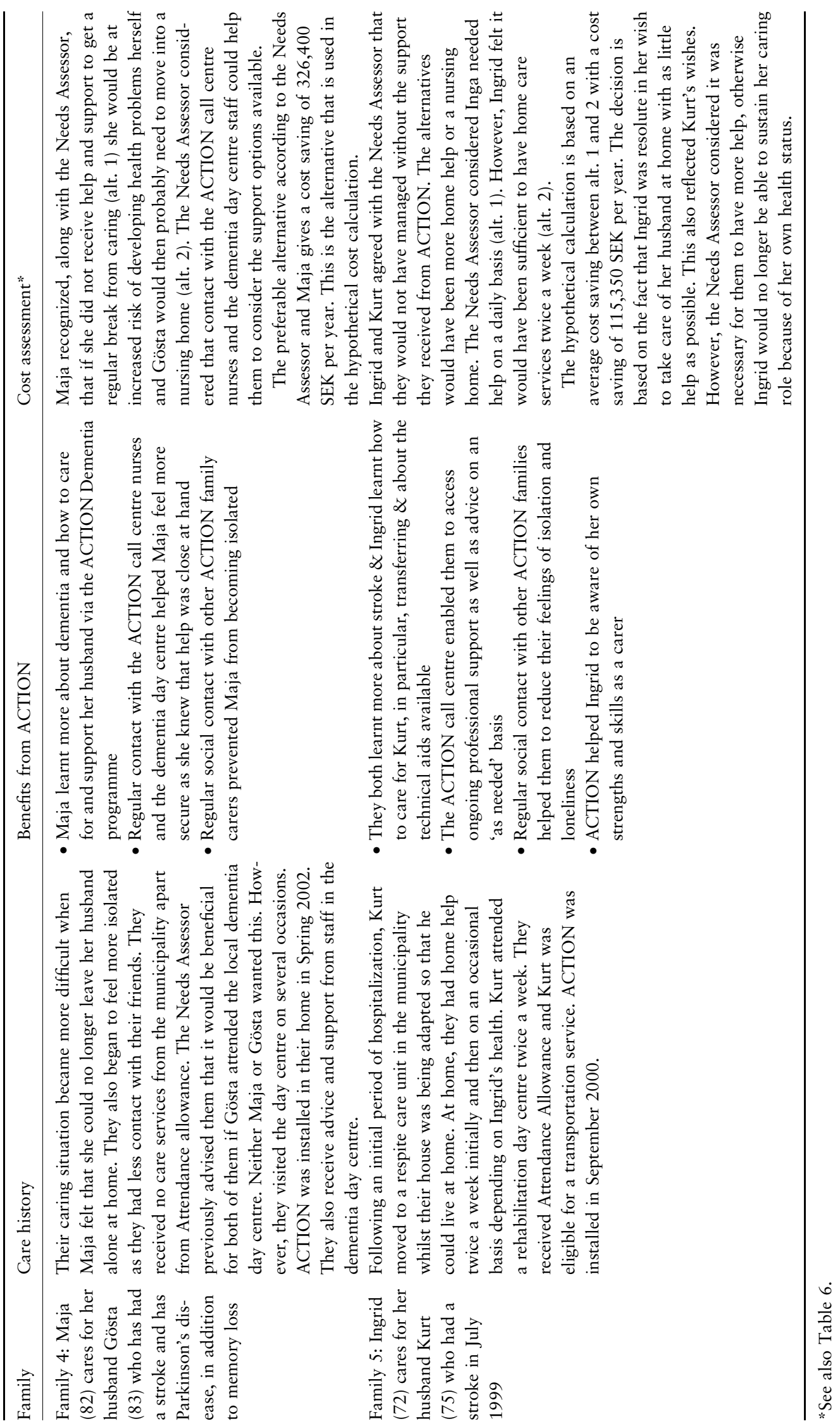


Table 6 Actual care costs and hypothetical cost savings using ACTION per family per year in Swedish Crowns*

\begin{tabular}{|c|c|c|c|c|c|}
\hline & \multirow[b]{2}{*}{ Care services } & \multirow{2}{*}{$\begin{array}{l}\text { Actual cost using } \\
\text { ACTION }^{\dagger}\end{array}$} & \multicolumn{2}{|c|}{$\begin{array}{l}\text { Estimated costs not using } \\
\text { ACTION }^{\dagger}\end{array}$} & \multirow{2}{*}{$\begin{array}{l}\text { Cost saving using } \\
\text { ACTION }^{\dagger}\end{array}$} \\
\hline & & & Alt. 1 & Alt. 2 & \\
\hline \multirow[t]{8}{*}{ Family 1} & Day care once a week & 33,800 & & & \\
\hline & Attendance Allowance & 14,112 & & & \\
\hline & ACTION & 25,800 & & & \\
\hline & Home help, once a week & 14,560 & & & \\
\hline & Home help, twice a month & & & 7,280 & \\
\hline & Respite care & & & 227,500 & \\
\hline & Nursing home & & 328,500 & & \\
\hline & Total cost & 88,300 & 328,500 & 234,800 & 146,500 \\
\hline \multirow[t]{6}{*}{ Family 2} & Attendance allowance & 14,112 & & & \\
\hline & ACTION & 25,800 & & & \\
\hline & Respite care, four times a year & 70,000 & & & \\
\hline & Respite care, 2 weeks per month & & & 227,500 & \\
\hline & Nursing home & & 328,500 & & \\
\hline & Total cost ${ }^{+}$ & 109,900 & 328,500 & 227,500 & 117,600 \\
\hline \multirow[t]{6}{*}{ Family 3} & Day care one day per week & 16,640 & & & \\
\hline & Attendance allowance & 14,520 & & & \\
\hline & ACTION & 25,800 & & & \\
\hline & Home help, 2 people 2 times/day & & 439,460 & & \\
\hline & Nursing home & & & 401,000 & \\
\hline & Total cost $\mathrm{t}^{+}$ & 57,000 & 439,500 & 401,000 & 382,500 \\
\hline \multirow[t]{5}{*}{ Family 4} & Attendance allowance & 14,520 & 14,520 & & \\
\hline & ACTION & 25,800 & 25,800 & & \\
\hline & Day care 1 day per week & & 34,320 & & \\
\hline & Nursing home & & & 401,000 & \\
\hline & Total cost ${ }^{\ddagger}$ & 40,300 & 74,600 & 401,000 & 326,400 \\
\hline \multirow[t]{6}{*}{ Family 5} & Day care twice a week & 33,280 & 33,280 & 33,280 & \\
\hline & Attendance allowance & 14,520 & 14,520 & 14,520 & \\
\hline & ACTION & 25,800 & & & \\
\hline & Home help, 2 people 2 times/week & & 62,600 & & \\
\hline & Home help, 2 people 2 times/day & & & 219,730 & \\
\hline & Total cost & 73,600 & 110,400 & 267,500 & 115,400 \\
\hline Average & & 73,800 & 256,300 & 306,360 & 217,700 \\
\hline
\end{tabular}

"Exchange rate 28.6.2002: 1 EUR = 9.08 SEK, 1 GBP = 14.01 SEK, 1 USD = 9.16 SEK (The Swedish Riksbank).

${ }^{\dagger}$ See also Table 5.

${ }^{*}$ Rounded to closest 100 Crowns.

the estimations are not entirely accurate. To make the estimations as credible and objective as possible, need assessors with extensive experience of assessing older people's needs and who were also familiar with the families' situations were closely involved.

As to the question of whether the comparator was appropriate, we consider that ACTION does not really have an appropriate comparator because it is a new service that empowers older people and their carers by enabling them to make informed decisions about their caring situation. Thus, there are associated difficulties of developing appropriate outcomes that are sufficiently sensitive to measure the effect of ACTION, given that services such as this are often preventive in nature and the majority of older people and their carers have chronic progressive health conditions (Magnusson et al. 2004).

The question of whether the quality of the medical evidence is adequate links to the previous issue about the comparator. Mair et al. (2000) and Whitten et al. (2002) argue that it is usually assumed that the benefits of the traditional service and the ICT-based service are equal, which rarely is the case. As previously explained, it is difficult to compare the benefits of ACTION with those of nursing home or more help at home, given the different aims of the services. 
As there is not any appropriate comparator available, the cost description analysis was carried out in relation to the total care cost savings for the five families.

In answer to the question whether appropriate costs and benefits were considered, it has to be acknowledged that future costs were not included. Future costs for equipment and communications will probably decrease because of increased supply and demand in ICT services by computer literate adults of working age (Ballabio \& Moran 1998). However, the expectations and wishes for higher specifications and more sophisticated solutions among the next generation of older people is likely to increase (Cowan \& Turner Smith 1999). Moreover, the issue of technology obsolescence was not taken into account in the cost description analysis. However, to minimize this possibility, ACTION worked with 'state of the art' technology in research and 'off the shelf' equipment and solutions (Kraner et al. 1999). No costs were included for further research and development work. The analysis only included costs for maintenance of the service. This is a weakness in the study that must be addressed in future cost effectiveness work, which would need to include a comprehensive sensitivity analysis to take into account such issues as well as the effect of marginal costs and short-term vs. long-time savings.

Another important question is whether an adjustment of costs and benefits should be made for differential timing. The case cost description analysis was carried out at one particular point in time, as opposed to using a longitudinal design. Thus, short-term cost savings with ACTION may be feasible as a result of more optimal use of home care services, respite services and delayed entry to institutional care. However, in the long-term, this could easily be off-set by an increased demand for home-based IT services, given the current high levels of unmet existing needs amongst older people and their carers in the community (Magnusson et al. 2004).

No marginal cost analysis was undertaken, which is another important issue raised by Mair et al. (2000) and Whitten et al. (2002). However, we consider that the marginal costs for a new user are largely the same as for existing users, because the main cost is equipment, communication and support. Additional services, such as virtual home visits by physicians, monitoring health status and alarm systems, can easily be added to the ACTION service at a reasonable cost as the ACTION families already have computer, videophone, broadband and Internet access.

Having acknowledged the main limitations of the ACTION case study cost analysis, it is important to consider the strengths of the study. In answer to the question whether there was a clear hypothesis, the study had a clear precise hypothesis that included the local context.
In response to the question of whether there was a clear statement about whose perspective was used to asses costeffectiveness, our cost study was conducted from the users' perspective, namely the family carers and, wherever possible, the older person they cared for, but also from the professional providers' perspective. This is in contrast to the majority of cost studies, which only focus on professionals' views (Mair et al. 2000, Whitten et al. 2002). The case studies vividly highlight the benefits of ACTION for older family carers who are resolute in their desire to care for their aged partner at home, and wish to retain as much control as possible over their caring situation. In particular, there were increases in their perceived independence, autonomy, self-esteem and caring competence, and a major reduction in social isolation.

Finally, we need to consider whether the analysis was appropriate to the local environment. This can be seen to be the case, as all the key players were actively involved, including older people, families and practitioners in both the municipalities (Magnusson et al. 2005).

However, the main strength of the study lies in the events that followed the evaluation, as both municipalities decided that ACTION would become part of their family carer support services. In reaching this decision, local politicians considered the evidence available from the evaluation of the Swedish ACTION service, including the quality of life benefits for older people and their family carers, enhanced work satisfaction of nurses and other professionals directly involved in the project, and the cost study data (L. Magnusson, I. Eriksson, F. Edberg, P.Svensson \& R. Lidskog unpublished data). We firmly believe that the politicians would not have decided to continue with ACTION without such multiple sources of evidence to support their decision.

Clearly, it is not possible to generalize from the results of this small cost study. However, it can be argued that it is possible to replicate the evaluation of ACTION in other municipalities across Sweden, as the evaluation work was conducted in municipalities with similar geographical and demographic circumstances to other municipalities in Sweden. However, it is important that future cost studies address the key limitations raised in our discussion.

It should also be possible to replicate the evaluation work in other European countries, as ACTION began as an EU-project in five partner countries. Quality of life and usability results were positive, and the developments to the Swedish ACTION service were based on the temporal model for family care support and user involvement methodology that informed the original study (Hanson et al. 1999a, Magnusson et al. 2002a). However, research and development work would also need to involve translation and cultural adaptation, which was not costed in the original EU project. 


\section{What is already known about this topic}

- Nurses working in community care need to explore the potential of information and communication technology-based support services as an innovative and costeffective way of working.

- The current evidence base on the cost-effectiveness of technology-based services for older people and their families is relatively weak and further research in this area is needed.

\section{What this paper adds}

- Technology-based support services have the potential to empower frail older people living at home and their family carers whilst yielding cost savings in community care services.

- Partnership is important when working with older people, their family carers, nurses and managers in order to transform an innovative project into a costeffective mainstream service.

\section{Conclusion}

This paper has highlighted the complexity of evaluating the cost effectiveness of ICT-based support services. The next step is to take the lessons learned from the initial cost study and to conduct a full randomized controlled trial and a detailed sensitivity analysis.

However, the success of the study locally demonstrates what can be achieved. All too often innovative services are never adopted after the initial financial support has been withdrawn. This study has indicated that this need not be the case. In response to demographic challenges and rapid developments in our current information society, nurse managers might more actively explore the potential of innovative ICT-based support solutions for older people and their carers in their local communities by involving other decision-makers, practitioners and service users. Finally, nurse educators at all levels need to teach nurses about the current evidence base for the use of ICT in health and social care in the community.

\section{Acknowledgements}

The Swedish ACTION project was supported by the Ministry of Social Affairs, University College of Borås, ÄldreVäst Sjuhärad, the West Sweden Region and Borås and Mark municipalities. The authors thank all the families and practitioners that have participated in the ACTION project, without whom the study would not have been possible. Finally, the authors would like to thank Professor Inga Wernasson, University of Gothenburg and Professor Mike Nolan, University of Sheffield for kindly reviewing an earlier draft of this paper.

\section{Author contributions}

LM and EH were responsible for the study conception and design, drafting of the manuscript and obtained funding; LM performed the data collection and analysis; EH made critical revisions to the paper and supervised.

\section{References}

Andersson N.-B., Hanson E. \& Magnusson L. (2002) Views of family carers and older people of information technology. British Journal of Nursing 11, 827-831.

Audit Commission (2004) Assistive Technology Independence and Well-being 2. National Report, Audit Commission Publications, Wetherby.

Ballabio E. \& Moran R. (1998) Addressing the Needs and Potential of Older People and People with Disabilities in the Information Society: An RTD Approach for the European Union. EC DGXIII, Telecommunications, Information Market and Exploitation of Research, Brussels.

Board of Health and Welfare Sweden (2002) Nationell handlingsplan för äldrepolitiken. Slut rapport (National guidelines for elderly policy, Final report), Board of Health and Welfare Sweden, Stockholm.

Board of Health and Welfare Sweden (2004a) Äldres levnadsförhållanden 1988-2002. Hälsa, funktionsförmåga och vård -och omsorgsmönster [Older People's Living Circumstances 1988-2002. Health, Functional Ability and Patterns of Statutory Care]. Board of Health and Welfare Sweden, Stockholm.

Board of Health and Welfare Sweden (2004b) Framtidens anhörigomsorg [Family Carer Support in the Future]. Board of Health and Welfare Sweden, Stockholm.

Cowan D. \& Turner Smith A. (1999) The Role of Assistive Technology in Alternative Models of Health Care for Older People, Appendix 4, Research volume 2, With Respect to Old Age: Long Term Care-Rights and Responsibilities, HMSO, 325, London.

Curry R.G., Trejo Rinoco M. \& Wardle D. (2003) Telecare: Using Information and Communication Technology to Support Independent Living for Older, Disabled and Vulnerable people, http:// www.icesdoh.org/downloads/ICT-older-people-July-2003.pdf.

Darkins A.W. \& Cary M.A. (2000) Telemedicine and Telehealth, Principles, Policies, performance and pitfalls. Springer Publications, New York.

Donelly M. (2002) Workers move across borders-do services also move? Plenary session presentation, European Home Care Seminar, Helsinki, Finland, May 4-6 2002, conference proceedings.

Flatley Brennan P., Moore S. \& Smyth K. (1995) The effects of a special computer network on caregivers of persons with Alzheimer's disease. Nursing Research 44, 166-172. 
Håkansson S. \& Gavelin C. (2000) What do we really know about the cost-effectiveness of telemedicine? Journal of Telemedicine and Telecare 6(S1), 133-136.

Hailey D., Roine R. \& Ohinmaa A. (2002) Systematic review of evidence for the benefits of telemedicine. Journal of Telemedicine and Telecare $8(\mathrm{~S} 1), 1-7$.

Hanson E. \& Clarke A. (2000) The role of telematics in assisting family carers and frail older people at home. Health and Social Care in the Community 8, 232-241.

Hanson E., Tetley J. \& Clarke A. (1999a) A multimedia intervention to support family caregivers. The Gerontologist 39, 736-741.

Hanson E., Tetley J. \& Clarke A. (1999b) Respite care for frail older people and their family carers: concept analysis and user focus group findings of a pan European Nursing Research project. Journal of Advanced Nursing 30, 1396-1407.

Hanson E., Tetley J. \& Shewan J. (2000) Supporting family carers using interactive multimedia. British Journal of Nursing 9, 713-719.

Hanson E., Magnusson L., Oscarsson T. \& Nolan M. (2002) Case study: benefits of IT for older people and their carers. British Journal of Nursing 11, 867-874.

Jennett P., Affleck Hall L., Hailey D., Ohinmaa A., Anderson C., Thomas R., Young B., Lorenzetti D. \& Scott R.E. (2003) The socio-economic impact of telehealth: a systematic review. Journal of Telemedicine and Telecare 9, 311-320.

Johansson L., Sundström G. \& Hassing L.B. (2003) State down, offspring up: the substitution issue in old-age care reversed in Sweden. Ageing and Society 23, 269-280.

Kraner M., Emery D., Cvetkovic R., Procter P. \& Smythe C. (1999) Information and communication systems for the assistance of carers based on ACTION. Medical Informatics 24, 233-248.

Magnusson L. \& Hanson E. (2003) Ethical issues arising from a research, technology and development project to support frail older people and their family carers at home. Health and Social Care in the Community 11, 431-439.

Magnusson L. \& Hanson E. (2004) Working together with older people and their family carers to research and develop responsive ICT support services. Health Telematics Journal 10, $83-88$.

Magnusson L., Berthold H., Chambers C., Brito L., Emery D. \& Daly T. (1998) Using telematics with older people: the ACTION project. Nursing Standard 13(5), 36-40.

Magnusson L., Berthold H., Hanson E., Chambers M., Brito L. \& O'Reilly A. (1999) Carers tap into the information highway. Nursing Times 95, 48-50.
Magnusson L., Hanson E., Chambers M., Berthold H., Brito L. \& Daly T. (2002a) Supporting family carers through the use of information technology - the EU project ACTION. International Journal of Nursing Studies 39, 369-381.

Magnusson L., Hanson E. \& Nolan M. (2002b) Assisting carers using the ACTION model for working with family carers. British Journal of Nursing 11, 759-763.

Magnusson L., Hanson E. \& Borg M. (2004) A literature review study of Information and Communication Technology as a support for frail older people living at home and their family carers. Technology and Disability 16, 223-235. 14, 1-13.

Magnusson L., Hanson E. \& Nolan M. (2005) The impact of information and communication technology on family carers of older people and professionals in Sweden. Ageing and Society 25, 693-714.

Mair F.S., Haycox A., May C. \& Williams T. (2000) A review of telemedicine cost-effectiveness studies. Journal of Telemedicine and Telecare 6(S1), 38-40.

Nolan M., Grant G. \& Keady J. (1996) Understanding Family Care. Open University Press, Buckingham.

Nolan M., Keady J., Grant G. \& Lundh U. (2003) Introduction: why another book on family care? In Partnerships in Family Care: Understanding the Caregiving Career (Nolan M., Lundh U., Grant G. \& Keady J., eds), Open University Press, Maidenhead, pp. 2-12.

Øvretveit J. (1998) Evaluating Health Interventions. Open University Press, Buckingham, p. 168.

Qureshi H., Bamford C., Nicholas E., Patmore C. \& Harris J.C. (2000) Outcomes in Social Care Practice: Developing an Outcome Focus in Care Management and Use surveys. Social Policy Research Unit, University of York, York.

Schulz R. (2001) Some critical issues in caregiver intervention research. Aging and Mental Health 5(Suppl. 1), S112-S115.

Stake R.E. (2000) Case studies. In: Handbook of Qualitative Research, 2nd edn (Denzin N.K. \& Lincoln Y.S., eds), Sage, Thousand Oaks, pp. 236-247.

Tetley J. \& Hanson E. (2000) Participatory research. Nurse Researcher 8, 69-88.

Whitten P., Mair F., Haycox A., May C., Williams T. \& Hellmich S. (2002) Systematic review of cost effectiveness of studies of telemedicine interventions. BMJ 324, 1434-1437.

Wootton R. (2001) Recent advances. Telemedicine. BMJ 323, 557560 . 